$\xi=-1$

\title{
Tree shaped fractal antenna with multiband characteristics
}

\author{
B T P Madhav ${ }^{1 *}$, V Subba Reddy ${ }^{1}$, D. Rajasekar Reddy ${ }^{1}$, K. Ravi Sankar ${ }^{1}$, E. V. S. Harsha Ramanujan ${ }^{1}$, \\ V. V. Surya Prakash ${ }^{1}$, M. Venkateshwara Rao ${ }^{1}$ \\ ${ }^{1}$ Department of ECE, Koneru Lakshmaiah Education Foundation, Andhra Pradesh, India-522502 \\ *Corresponding author E-mail: btpmadhav@kluniversity.in
}

\begin{abstract}
A tree shaped fractal antenna with U shaped slot and W-shaped slot has been designed and analyzed in this article by using ANSYS electromagnetic desktop 17. The proposed antenna is analyzed taking FR4 substrate is taken as the substrate material. The proposed antenna exhibits multiband characteristics $(2.75-3.17 \mathrm{GHz}, 4.1-4.8 \mathrm{GHz}, 5.1-5.3 \mathrm{GHz}$ and $5.4-6.3 \mathrm{GHz}, 7.21-12.8 \mathrm{GHz})$ in the Ultra-wide band region. The path that is radiating by superposition of the rectangular patches and multiple-band operating frequency is obtained by increasing the U-shapes slots and w-shaped slot on the patch. The improvement in the impedance characteristics between the adjacent frequencies is achieved by using defected ground structure (DGS) on the ground plane as to cover the region of UWB application (3.1-10.6GHz). The proposed antenna works in the applications like Wi-Max, Weather forecasting RADAR systems and WLAN.
\end{abstract}

Keywords: Defected Ground Structure (DGS); Multiband; Fractal Antenna.

\section{Introduction}

Antennas is a vital role in modern wireless communication systems. Now days, there is a huge demand for compact size antennas because of the properties like less cost, versatility, ease in portability and their conformal nature. Although micro strip antenna serves these properties, some of the disadvantages such as low gain, narrow band width and excitation of surface waves are inevitable. To overcome the disadvantage of low gain, micro strip antenna array technology is being introduced. This technology enables to improve certain characteristics of antenna like desired radiation pattern, high gain and radiation pattern in desired direction. In [1] using antenna array Increased in antenna properties like gain and band width are produced. To obtain the radiation pattern there are different types of topologies for antenna arrays based upon amplitude and phase variations such as same amplitude and varying phase difference, varying amplitude and same phase difference, varying amplitude and varying phase difference. Uniform arrays can be constructed with great ease [2], [4] and can be fabricated easily. In general, UWB systems have sufficiently broad operating band width for high gain and directivity in desired directions. In [5], dual polarization of microstrip antenna array is analyzed for WLAN applications this article describes the simulation and analysis of a CPW fed four element linear antenna array for wireless applications and surveillance radar. A single element is attached with the $1^{\times} 4$ feeding networks. The variation in results can be observed by inserting and removing ' $U$ ' shaped slots on the surface of the radiating element. After analyzing the results obtained for different models, the optimum model is considered for fabrication. The fabricated antenna is tested with combinational analyser such that a good agreement is obtained between simulated and measured results [6-7]. There is an advancement has been taken place in the development of slot antennas by varying the shape and size of the slots. By this we can convey that changes in impedance bandwidth and there will be increment of antenna working frequency range. The design of slot antenna is simpler and also, they are robust in nature [9-12]. Radiation pattern distribution can be determined from the shape and size of the antenna. Previously L-shaped slot antenna, U-shaped slot antenna, and rectangular slot antenna with stubs and circular slot antennas were designed, but from the literature review it has been concluded that these antennas have a drawback of complex structure and limited bandwidth. In printed slot antennas alignment problems occur due to multiple layers of the antenna, hence we have adapted CPW feed line technique which is a single layer structure [13-15]. Also, $\mathrm{CPW}$ has lower loss than the micro strip line. When we use a CPW slot antenna it is easier to integrate it with a system that utilizes fiber optics. Good impedance match can be achieved at these range with the help of CPW feed line instead of normal microstrip feed technique [16-21]. Also, CPW has ground on the same plane of the patch so this structure is simple and has single metallic layer. Hence in this paper we presented a novel compact CPW-fed printed with U-slot and W shaped slots. The proposed antenna exhibits multiband characteristics in ultrawide band region. ANSYS HFSS 17 is used to analyze the proposed antenna. The proposed antenna and its results has been discussed in subsequent sections.

\section{Antenna design}

A compact tree shaped fractal of size $23 \mathrm{~mm} * 30 \mathrm{~mm}$ which is designed on the FR4 substrate having dielectric constant of 4.4 and loss tangent 0.02 is taken and analysed using commercially equipped EM tool ANSYS electromagnetic desktop 17. The proposed antenna is demonstrated iteration wise as shown in below fig 1. 
(A)

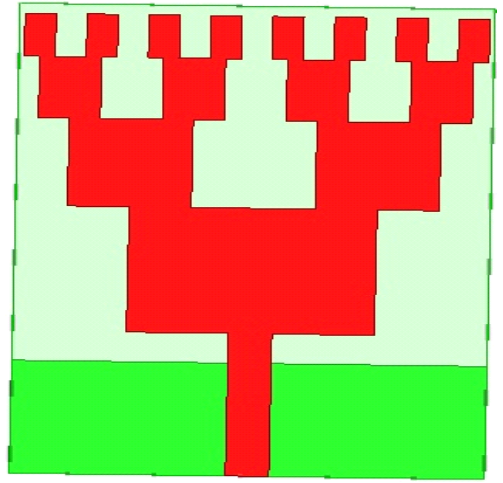

(B)

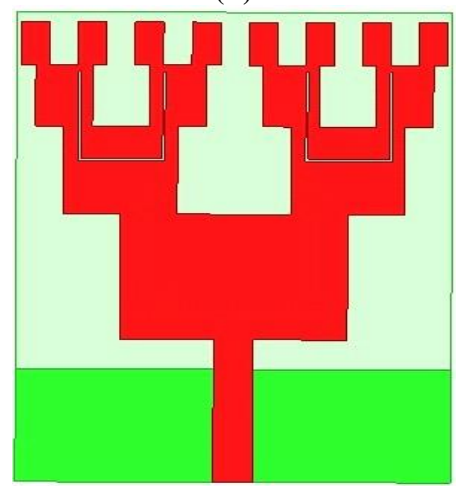

(C)

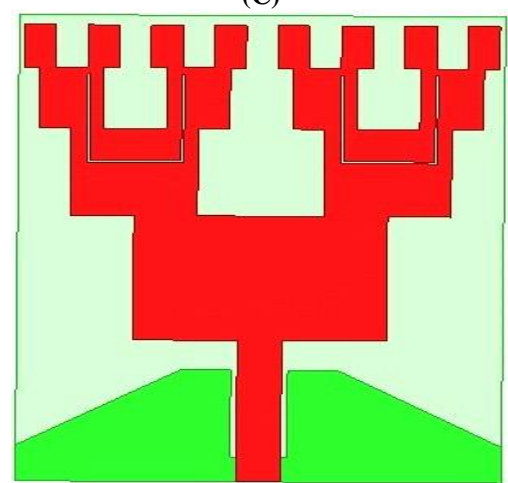

Fig. 1: Iterations of the Antenna Models (A) Iteration 1 (B) Iteration 2 Having U Slot on the Patch (C) Iteration 3 with U Slots and Modified Ground (DGS).

Table 1: Design Parameters of Proposed Antenna (All are in Mm)

\begin{tabular}{|c|c|c|c|c|c|c|c|c|c|c|c|c|}
\hline $\mathrm{W}$ & $\mathrm{L}$ & Wf & Lf & $\mathrm{C}$ & $\mathrm{D}$ & Ts & 11 & 12 & L3 & $\mathrm{L} 4$ & L5 & W1 \\
\hline 23 & 30 & 2 & 9.1 & 8 & 12 & 0.15 & 8.5 & 8.2 & 4.5 & 3.5 & 2.5 & 5.9 \\
\hline W2 & & & W4 & Wg1 & & $\mathrm{Lg} 1$ & ws & 1s & \multicolumn{2}{|c|}{ Lg2 } & & $\mathrm{h}$ \\
\hline
\end{tabular}

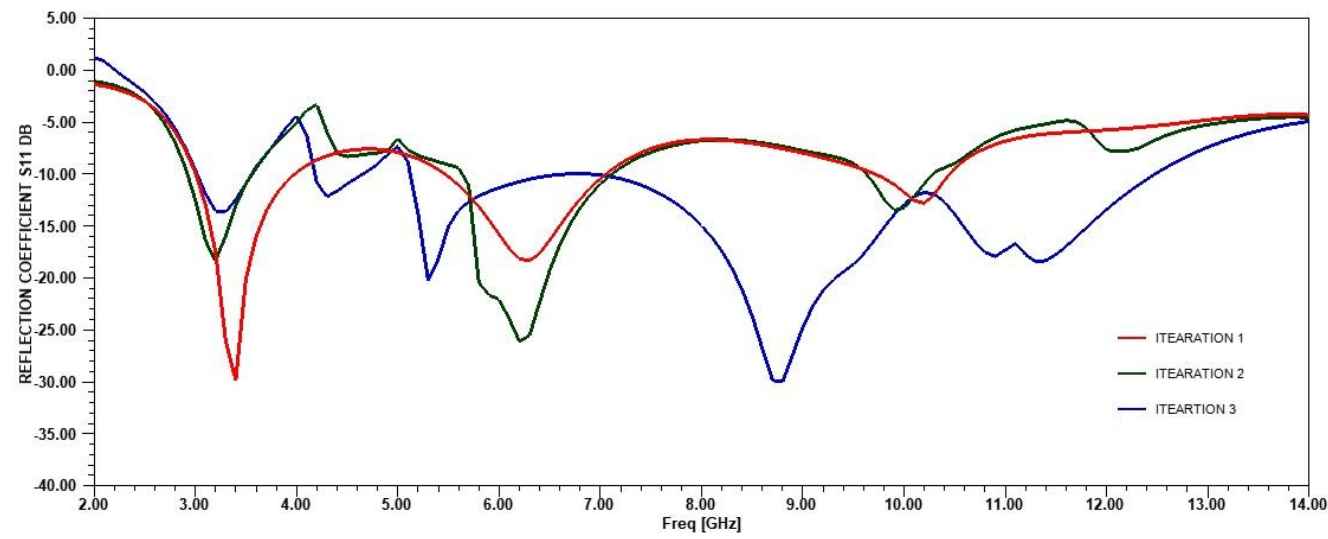

Fig. 2: Reflection Coefficient of Three Iterations of the Antenna.

After analysing, the parameters of proposed antenna are shown in Table. The scaling factor $a=0.7, b=0.5$. All iterations have been analysed on the FR-4 substrate $(\mathrm{W} \times \mathrm{L})$ which is having relative permittivity $(\varepsilon r)=4.4$, loss tangent $(\delta)=0.02$ and of thickness $1 \mathrm{~mm}$.Wf and $\mathrm{Lf}$ is the width and length of the feedline the antenna. A ground plane with a DGS structure is taken to improve the impedance characteristics in the UWB band. The DGS ground plane has two6 symmetrically levelled corners and a rectangular gap with a size of Ls $\times W$ s on a rectangular ground plane. Repeatedly two U-shaped slots are placed on the patch with width of ts as to suppress the interference due to Weather RADAR systems $(4 \mathrm{GHz})$ and WLAN $(5.7 \mathrm{GHz})$ bands and another X-band application

The performance of the antenna with different iteration stages with U-shaped slot without DGS and Inverted U-shaped slot (proposed model) with DGS were simulated to analyse the influences of fractal iteration times on the performance of the antenna.

In addition, the U-shaped slot in the ground plane is very important and it is covered with the DGS to the performance of the antenna, because the capacitance introduced at rectangular gap. Fig. 2 shows the reflection coefficient for different iterations of the antenna with having the U-shaped slots and defected ground plane. Figure indicates at first antenna model iteration the single notch appears where as in the second antenna model single notched only appear. The third antenna model behaves in dual notch band characteristics. In this study, the sizes of the rectangular gap with U-Shaped Slot are divided into different groups. The impedance matching of the antenna can be improved with length $\mathrm{LS}=5.6 \mathrm{~mm}$ and width $\mathrm{WS}=2.7 \mathrm{~mm}$. From this study, the reflection coefficient of the operating bandwidth can be varied by changing the value of the U-Slot gap and Inverted U-shaped slot each affiliation must include, at the very least, the name of the company and the name of the country where the author is based (e.g. Causal Productions Pty Ltd, Australia). Email address is compulsory for the corresponding author.

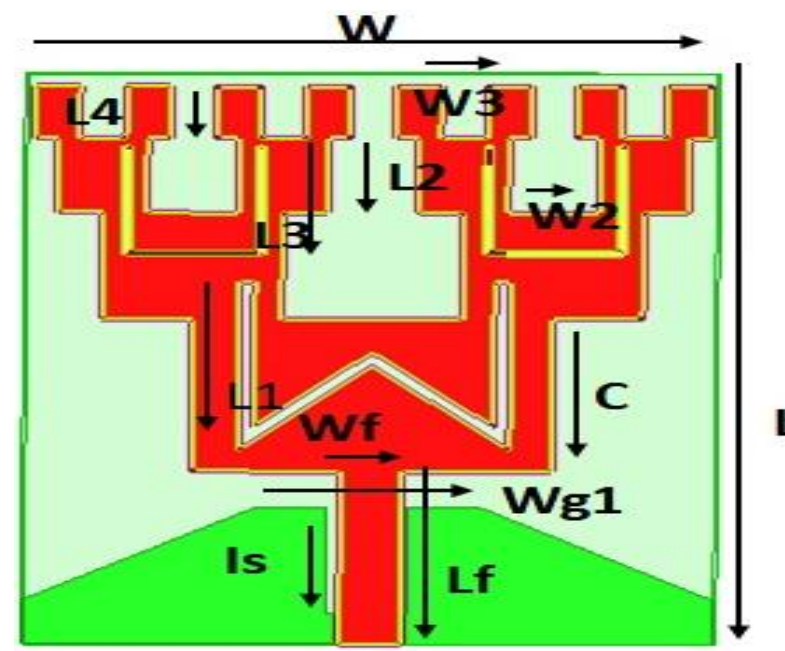

Fig. 3: Layout of the Proposed Antenna.

The proposed model of the antenna has been modified by attaching a U-shaped slot and w shaped slot from basic three iterations. Therefore because of changing these improvements in the structure the multiband characteristics has been obtained in the ultrawideband region. The results for the proposed model is shown in figure 4. Maximum return loss for the proposed antenna is ob- 
served at frequency range of $8.9 \mathrm{GHz}$.The proposed antenna has its applications at WLAN, weather RADAR systems and X-band bands.

\section{Results and discussions}

Return loss also known as reflection coefficient (S11) usually represents the discontinuity in the power of signal that is returned which is mainly caused due to impedance mismatch. The centre frequency of the antenna is $8.9 \mathrm{GHz}$ where we can observe maximum return loss of $-28 \mathrm{~dB}$ in figure 4 . Now, this shows that we have minimum power loss at $11.6 \mathrm{GHz}$ frequency.

Gain is a combinational representation of directivity and Radiation efficiency of the antenna. Gain in $\mathrm{dB}$ can be mathematically deduced from gain factor. For this antenna design the gain minimum is $0.5 \mathrm{~dB}$ and maximum is $6 \mathrm{~dB}$ which is shown in the figure 4.the formulae for the gain factor is
$\mathrm{G} \mathrm{dBi}=10 \log 10(\mathrm{G})$, where $\mathrm{G}$ is the gain factor of the antennA When gain is measured and averaged by considering all the directions instead of specific direction we get peak gain which is usually maximum gain of the antenna. For the proposed model it shows negative peak gain $(-6 \mathrm{~dB})$ at notch band but the $8 \mathrm{GHz}$ it shows maximum gain of $5.2 \mathrm{~dB}$ which exhibits maximum notch band Figure 6 and 7 represents Radiation pattern and radiation efficiency of the proposed antenna is achieved at different frequency ranges how gain is varied with respect to the radiation of the antenna in space. We achieved Quasi omni directional radiation pattern at the frequency range of $3.8 \mathrm{GHz}$ and $5 \mathrm{GHz}$ (Notch bands) and rest of the frequency ranges $4.3 \mathrm{GHz}, 5.6 \mathrm{GHz}, \mathrm{GHz}$ exhibits omni directional radiation pattern. The efficiency of the antenna is almost same in the working band but at the three notch bands a suppression in the antenna radiation efficiency is observe.

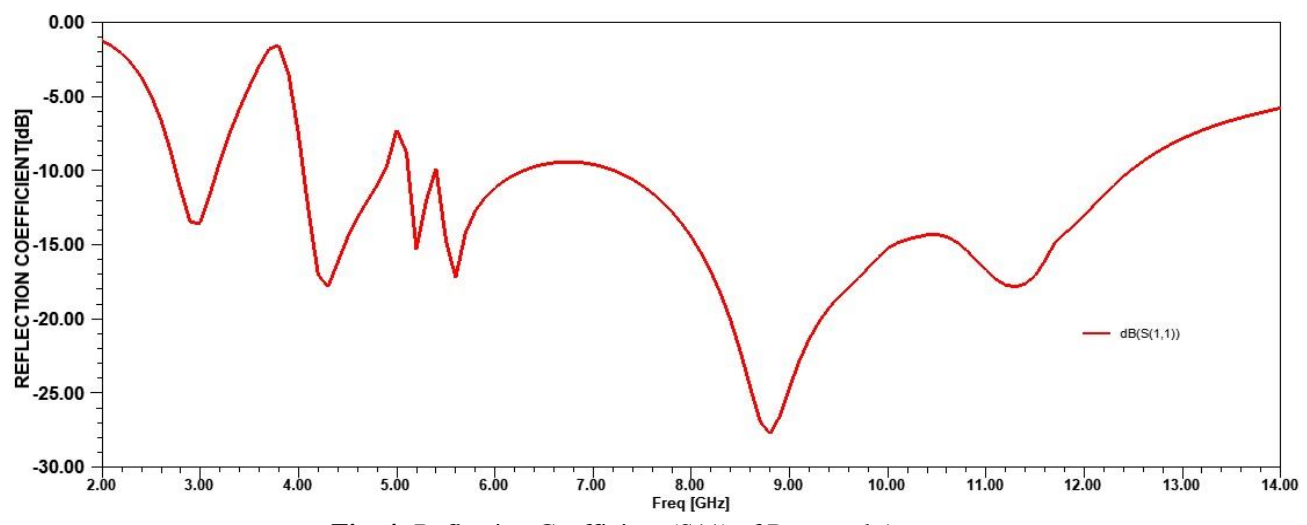

Fig. 4: Reflection Coefficient (S11) of Proposed Antenna

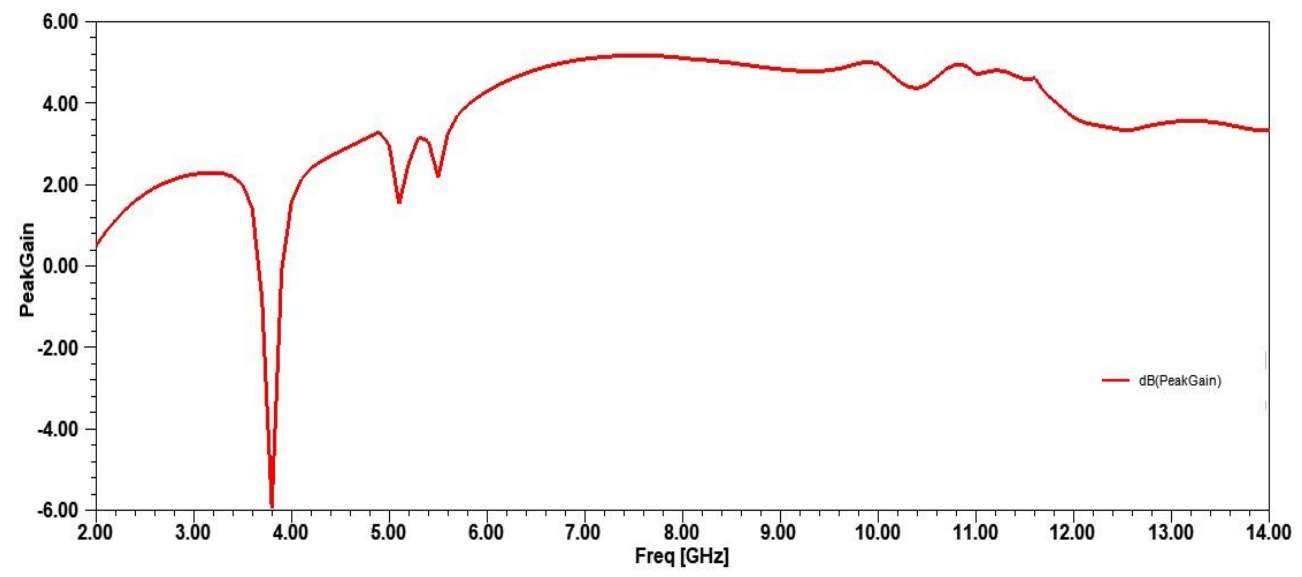

Fig. 5: Peak Gain vs. Frequency for the Proposed Antenna.

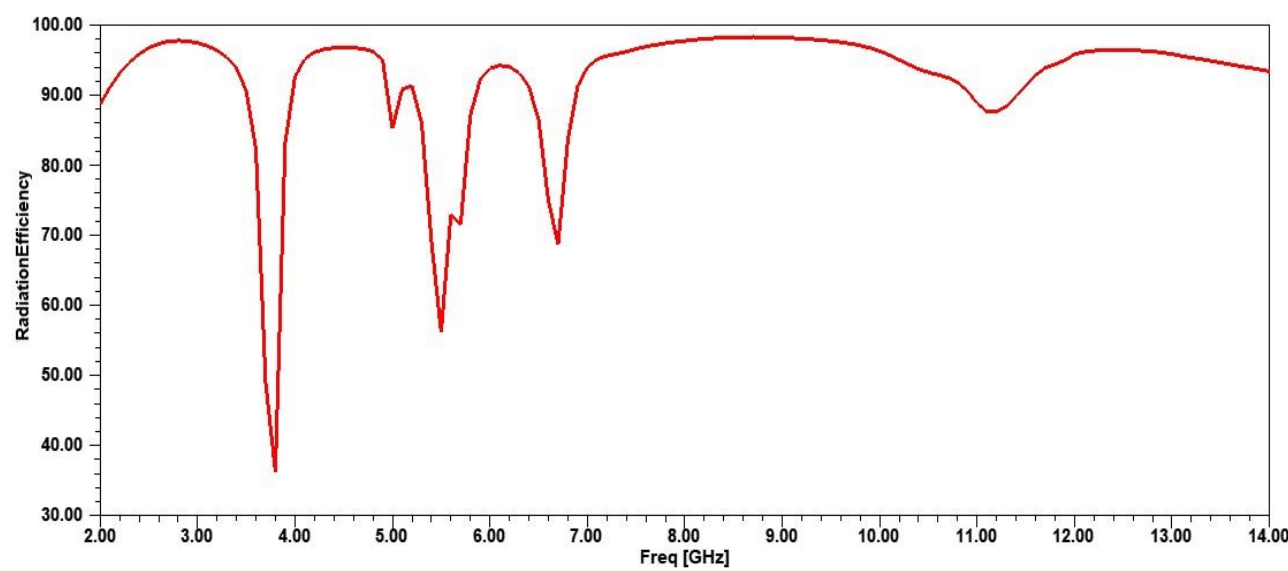

Fig. 6: Radiation Efficiency vs. Frequency for the Proposed Antenna. 

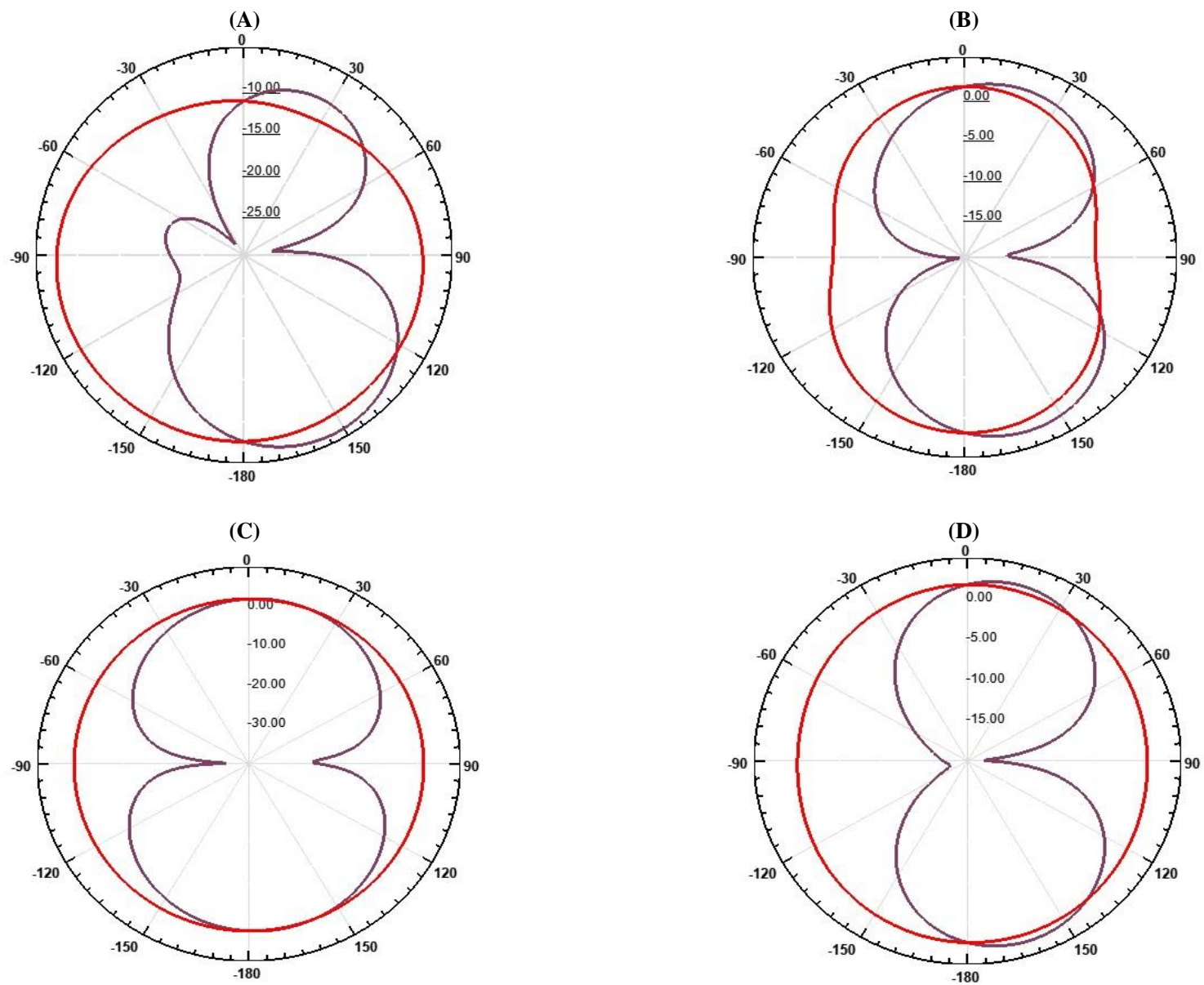

Fig. 7: Simulated Radiation Patterns for Xy-Plane (E-Plane) and Xz-Plane (H-Plane) for Notch Bands (A) 3.8ghz (B) 5.8ghz Working Bands (C) 4.3 Ghz. (D) $5.6 \mathrm{ghz}$.
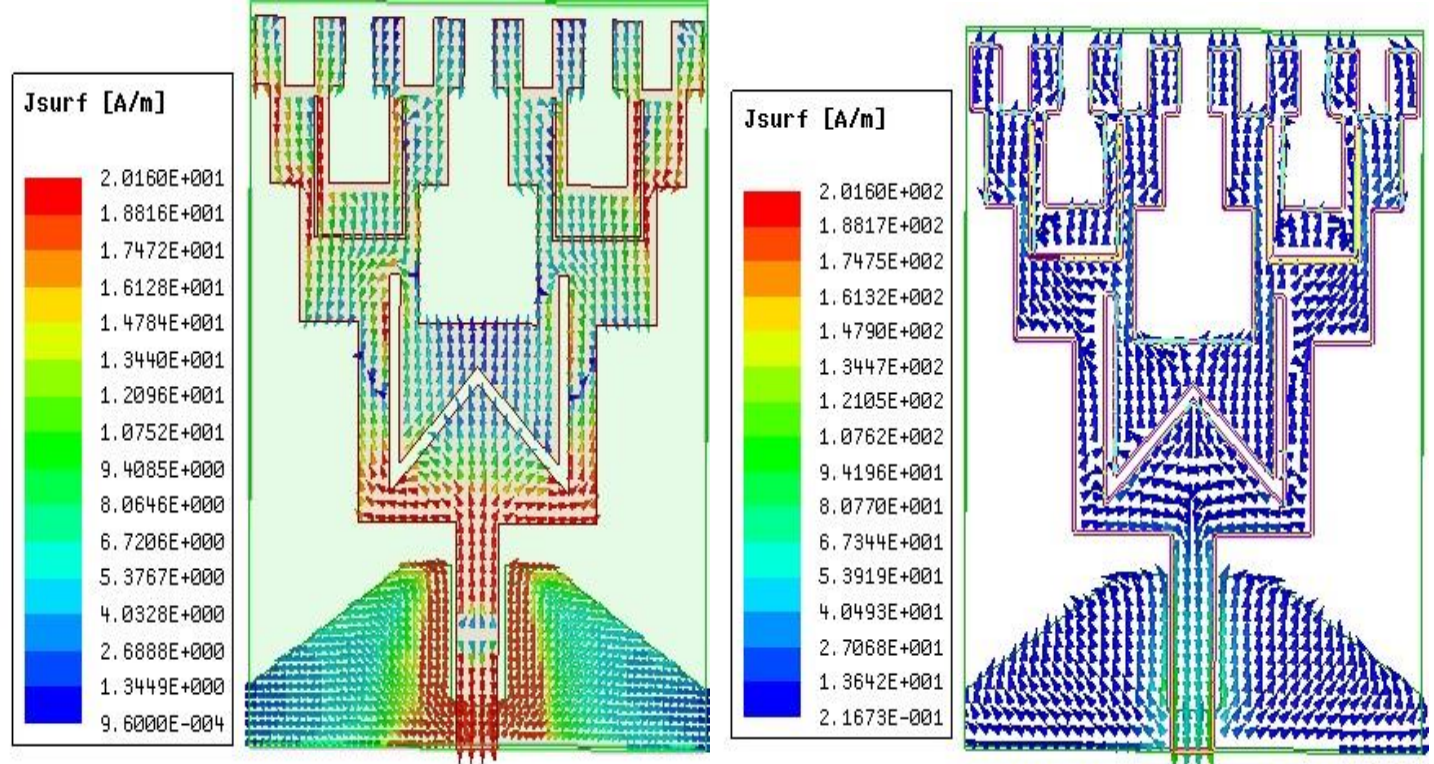

Fig. 7: Current Distribution of the Proposed Antenna at 3.8ghzv(Notch Band) and 4.3Ghzv(Working Band).

\section{Parametric study}

Figure 9 and figure 10 shows the parametric analysis of the proposed antenna by varying the parameters width and length of the ground ws and ls. Figure 9 shows the triple notch characteristics is seen at ws $=4.9 \mathrm{~mm}$. Similarly in Figure 10 we observe the parametric analysis of the proposed antenna by varying ls. 


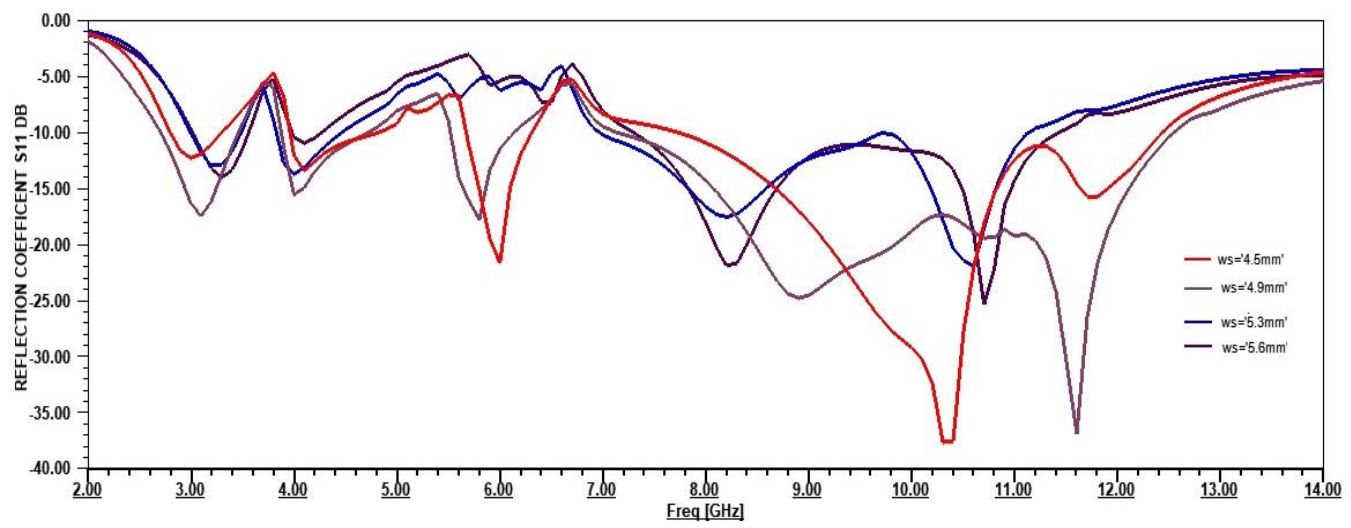

Fig. 9: Parametric Analysis by Varying the Parameter Ws.

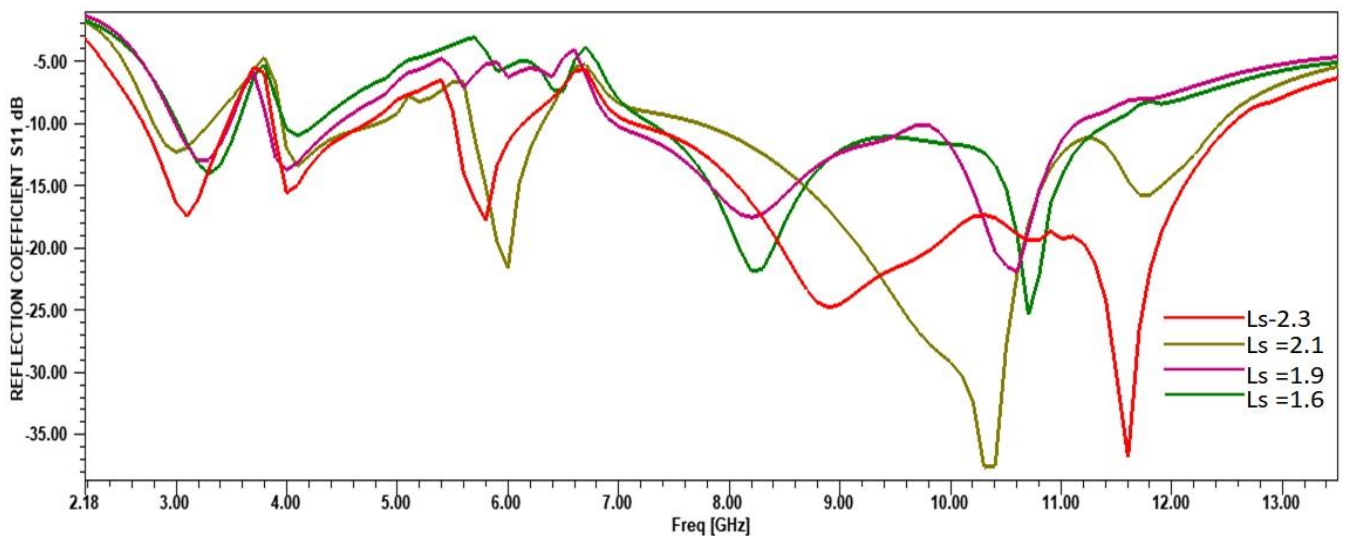

Fig. 9: Parametric Analysis by Varying the Parameter Ws.

\section{Conclusion}

A rectangle fractal antenna with $\mathrm{u}$ and $\mathrm{w}$ shaped slots are exhibiting the multi band characteristics is designed and characterized using ANSYS EM tool. Multiple resonant frequencies are obtained because U-shaped and w shaped slots. By introduction of U-shaped and Inverted for the proposed model we have obtained new resonances. The improvement of impendence characteristics is done by using Defected ground structure in the ground plane proposes UWB operation $(6.4-12.4 \mathrm{GHz})$.The multiband band characteristics which is obtained by Inverted U-shaped Slot used for the applications like Weather forecasting RADAR systems and WLAN and other X-band applications. The gain decreases at notch band $(-6 \mathrm{~dB})$ and at working band $(4 \mathrm{GHz})$ shows good correlation for working and notch bands. The Proposed antenna can be widely used in various ultrawide band applications.

\section{Acknowledgements}

The authors deeply express their gratitude to ALRC Research Centre, Department of ECE, K L University for their encouragement during this work. Further, we express our gratitude to DST through ECR/2016/000569, FIST SR/FST/ETI-316/2012 and EEQ/2016/000604.

\section{References}

[1] Norfishah Ab Wahab, "Microstrip Rectangular 4x1 Patch Array Antenna at $2.5 \mathrm{GHz}$ for WiMAX Application," IEEE computer society 2010

[2] B. Sai Sandeep, "Design and simulation of microstrip patch array antenna for wireless communications at $2.4 \mathrm{GHz}$," International Journal of Scientific \& Engineering Research, Volume 3 , Issue 11, November-2012
[3] Hsien-Wen Liu, Chia-Hao Ku, and Chang-Fa Yang, "Novel CPWFed Planar Monopole Antenna for WiMAX/WLAN Applications," IEEE Antennas and Wireless Propagation

[4] Letters, Vol. 9, April 2010.

[5] H. Wang, X. B. Huang, D. G. Fang. A single layer wideband U slot microstrip patch antenna array. IEEE antennas and wireless propag. lett. 2008(7): 9 12. https://doi.org/10.1109/LAWP.2007.914122.

[6] Shavit, R., Tzur, Y., and Spirtus, D, "Design of a new dualfrequency and dual-polarization microstrip element", IEEE Trans. Antennas Propag., vol 51, (7), pp. 1443-1451, July 2003 https://doi.org/10.1109/TAP.2003.813594.

[7] Muhammad Mahfuzul Alam, Md. Mustafizur Rahman Sonchoy, and Md. Osman Goni, "Design and Performance Analysis of Microstrip Array Antenna," Progress in Electromagnetics Research Symposium Proc., Aug. 2009, pp. 18-21

[8] Chen, H.-D., C.-Y.-D. Sim, J. Y. Wu, and T.-W. Chiu, Broadband high-gain microstrip array antennas for WiMAX base station," IEEE Trans. on Antennas and Propag., Vol. 60, 3977\{3980, 2012.

[9] George Casu, "Design and Implementation of Microstrip Patch Antenna Array," Military Technical Academy, Faculty of Electronics and Informatics, IEEE, 2014. https://doi.org/10.1109/ICComm.2014.6866738.

[10] J.J Xie, X.S. Ren, Y.Z. Yin, and S.L. Zuo, "Rhombic slot antenna design with a pair of straight strips and two U-shaped slots for WLAN/WiMAX applications", Microwave and Optical Technology Letters, Vol. 54, no.6, pp. 1466-1469, 2012 https://doi.org/10.1002/mop.26837.

[11] B. T. P. Madhav, Mounika Sanikommu, M. N. V. S. Pranoop, K. S. N. Manikanta Chandra Bose and B. Sriram Kumar, CPW Fed Antenna for Wideband Applications based on Tapered Step Ground and EBG Structure, Indian Journal of Science and Technology, ISSN: 0974-6846, Vol 8, Issue 9, May 2015, pp 119-127.

[12] ] T. G. Ma and S. K. Jeng, \&quot;Planar miniature tapered-slot- fed annular slot antennas for ultra-wideband radios,\&quot; IEEE Trans. Antennas Propag., vol 53, pp. 1194-1202, Mar. 2005. https://doi.org/10.1109/TAP.2004.842648.

[13] M. V. Reddiah Babu, Sarat K. Kotamraju, B. T. P. Madhav, Compact Serrated Notch Band Mimo Antenna For Uwb Applications, Arpn Journal Of Engineering And Applied Sciences, Issn 18196608, Vol. 11, No. 7, April 2016, Pp 4358-4369.

[14] Yi-Cheng Lin and Kuan-Jung Hung, \&quot;Compact Ultrawideband Rectangular Aperture Antenna and Band-Notched De- 
signs,\&quot; IEEETrans. Antennas Propag., vol. 54, NO. 11, Nov. 2006

[15] K V L Bhavani, Habibulla Khan, D Sreenivasa Rao, B T P Madhav, Dual Band Notched Planar Printed Antenna with Serrated Defected Ground Structure, Journal of Theoretical and Applied Information Technology, ISSN: 1992-8645, Vol 88, Issue 1, June 2016, pp 28 34.

[16] A. Kerkhoof and H. Ling. \&quot;A parametric study of bandnotched UWBplanar monopole antennas,\&quot; IEEE Antenna Propag Soc Int Symp Dig 2(2004), 1768-1771

[17] K V L Bhavani, Habibulla Khan, B T P Madhav, Wideband CPW Fed Monopole Fractal Antenna with Defected Ground Structure, Journal of Engineering and Applied Sciences, ISSN: 1816-949X, 2016, Vol 11, Issue 11, pp 2446-2454

[18] C. B. Dietrich, Jr., K. Dietze, J. R. Nealy, and W. L. Stutzman, "Spatial, polarization, and pattern diversity for wireless handheld terminals," IEEE Trans. Antennas Propag., vol.49, no. 9, pp. 12711281, Sep.2001. https://doi.org/10.1109/8.947018.

[19] D S Ramkiran, P Siddaiah, B T P Madhav, serrated circular fracta coplanar wave guide fed antennas for wideband and ultra-wideband applications, IJCTA, ISSN: 0974-5572, Vol 10, No 1, pp 259-266, 2017.

[20] B. Allen,M. Dohler, E. Okon,W. Q.Malik, A. K. Brown, and D. Edwards UWB Antenna and Propagation for Communications, Radar and Imaging. Hoboken, NJ, USA: Wiley, 2007.patients for six months. Journal of Clinical Nursing 16, 1082-1087. 